\title{
Effects of Diet on Insulin and Gastric Inhibitory Polypeptide Levels in Obese Children
}

\author{
I. DESCHAMPS, ${ }^{(20)}$ W. HEPTNER, J.-F. DESJEUX, V. BALTAKSE, S. MACHINOT, AND H. \\ LESTRADET \\ Groupe de Recherche sur le Diabète et la Nutrition chez l'Enfant, INSERM U. 83. Service de Pédiatrie du Professeur \\ LESTRADET, Université Paris VII and Hôpital Hérold, 75019 Paris, France [I. D., J.-F. D., V. B., S. M., H. L.], \\ and Hoechst A. G., Medizinische Abteilung H 840, 6 Frankfurt /M, Germany [W. H.]
}

\section{Summary}

To improve understanding of the relationships between gastric inhibitory polypeptide (GIP) and insulin secretion and food intake in obesity, immunoreactive insulin and immunoreactive GIP were measured in 5 obese children during PO glucose tolerance test carried out before and after diet.

Before diet, mean insulin levels were normal at fasting and rose after glucose ingestion. The mean fasting immunoreactive GIP level was very high $(1235 \pm 209 \mathrm{pg} / \mathrm{ml})$ compared to that of 8 healthy adult controls $(411 \pm 44 \mathrm{pg} / \mathrm{ml})$ and remained at this level throughout the test. There was only a short postabsorptive rise to $1515 \pm 158 \mathrm{pg} / \mathrm{ml}$ at $30 \mathrm{~min}$, which was not significantly different either from the patients' basal values or from the 30 -min control values $(1356 \pm 67 \mathrm{pg} / \mathrm{ml})$.

After dieting for 3 to 7 months, immunoreactive insulin responses returned to normal ranges. Concomitantly, both basal and total GIP release diminished significantly (basal GIP, $343 \pm 92$ $\mathrm{pg} / \mathrm{ml}$; area under the GIP curve, 3820 and $1694 \mathrm{pg} / \mathrm{ml} / \mathrm{hr}$ before and after diet, respectively). The postabsorptive GIP increment, however, rose significantly from $180 \mathrm{pg} / \mathrm{ml} / \mathrm{hr}$, before diet, to 665 $\mathrm{pg} / \mathrm{ml} / \mathrm{hr}$ afterwards.

These results might be compatible with the hypothesis that in obesity, hyperinsulinemia, and overactivity of the GIP cells are associated phenomena caused by overeating and reversed by reduced food intake. However, several contradictory findings remain unexplained. The discrepancy between insignificant postabsorptive GIP increments and elevated insulin responses before diet casts doubts on the causal relationship between GIP and insulin secretion. The small GIP rise might be due to a limited secretory capacity of the GIP cells or to a diminished stimulatory capacity of glucose. The constantly high level of GIP might reflect chronic hypersecretion and/or some defect in basal regulation and feedback control of GIP release.

The change caused by dietary measures in the GIP secretion pattern provides evidence that in obese children, basal GIP secretion is influenced by nutritional factors.

\section{Speculation}

In spite of the small number of observations, the present findings illustrate the complexity of the mechanisms governing the regulation of gastric inhibitory polypeptide and insulin release in obesity. It seems likely that basal gastric inhibitory polypeptide secretion is influenced by food intake, but further studies will be necessary to confirm that gastric inhibitory polypeptide plays a causal role in the hyperinsulinemia of obesity in children.

The pathogenesis of hyperinsulinemia associated with obesity is still poorly explained. In recent years, however, the role of nutritional factors in the development of hyperinsulinism has aroused growing interest. Experimental overnutrition in normal subjects $(12,15)$, as well as changes in the diet composition of normal (13) and obese subjects (14) led to rapid elevation of insulin levels. Increased insulin responses in adult and childhood obesity were improved or returned to normal ranges after reduction of food intake $(7,10,14)$. Furthermore, the existence in the intestinal mucosa of one or more substances capable of releasing insulin after food ingestion has been recognized $(2,5,19)$, and it is tempting to postulate that overactivity of this system might cause hyperinsulinemia in obesity. In this connection, duodenal insulin-releasing activity, as measured by its ability to release insulin from an in situ rat pancreas preparation, has been found to increase in obese subjects (18). The gastric inhibitory polypeptide (GIP) is at present the most likely gut hormone candidate for mediation of insulin secretion $(1,6,9)$. Following high-calory test meals, GIP was seen to be elevated in the plasma of obese adults, and this high level was associated with elevated insulin responses (4). After PO glucose loading, the results were slightly different: GIP and insulin responses rose significantly in obese subjects with pathologic glucose tolerance but not in those with normal PO glucose tolerance test (OGTT). Recent investigations in fasted or food-restricted obese adults demonstrated that dietary measures could reverse an excessive GIP response (16).

Nothing is known, however, about insulin stimulation by intestinal factors early in life during the obesity onset period. In previous studies of OGTT in obese children (8), we found that insulin responses increased independently of glucose tolerance, age of onset, or duration of obesity. Hyperinsulinism, however, could be reduced by diet (7).

The aim of the present study was to investigate whether in the early stages of obesity, increased insulin release following PO glucose ingestion is associated with elevated GIP concentrations and whether diet can reduce GIP levels, as it can insulin levels.

\section{PATIENTS AND METHODS}

Five obese children, 2 boys and 3 girls, aged from 6 to 13 years, were tested after obtaining their own and their parents' consent. Their degree of obesity, expressed as the difference in standard deviations (S.D.) between weight and height for age (see description in Ref. 7) ranged from 2.7 to 6.3 S.D. Obesity had started between the ages of 3 and 9 and had lasted for 3 to 5 years at the time of the test. Dietary investigation revealed that spontaneous food intake was hypercaloric in all five children (2800 to more than 3000 calories/day, whereas normal children of these ages take 1600 to 2200 calories/day) and contained increased amounts of lipids and simple sugars.

After a standard OGTT with $45 \mathrm{~g}$ glucose per $\mathrm{m}^{2}$ body surface, the children were put on a moderately restricted diet: 1200 to 1500 calories/day, depending on age, consisting of 45 to $50 \%$ carbohydrate, 30 to $35 \%$ lipids and 15 to $20 \%$ protein, divided into four equal meals. After three to seven months, a second OGTT was performed. Patients were advised to eat normal amounts of carbohydrates (at least $200 \mathrm{~g} /$ day) three days prior to testing. 
During the tests, plasma glucose was measured by the glucose oxidase method, immunoreactive insulin (IRI) was measured by radioimmunoassay (17) with separation on charcoal, and immunoreactive GIP (IRGIP) was measured by the technique of Kuzio et al. (11) with minor modifications according to Creutzfeld et al. (3). This assay measures "big" and "little" GIP. I ${ }^{125}$-labeled GIP was labeled by R. Ebert (Göttingen). The GIP antiserum, provided by J. C. Brown, did not cross-react with glucagon, secretin, CCK, or gastrin. The porcine GIP standard was also obtained from J. C. Brown. Interassay reproducibility was $243 \pm 29 \mathrm{pg} / \mathrm{ml}$, and the limit of detection was $60 \mathrm{pg} / \mathrm{ml}$.

For technical reasons, GIP testing in age-matched controls was not possible. IRGIP, measured in 8 healthy adults under identical conditions, served as reference.

\section{RESULTS}

The main clinical data for the five obese children are summarized in Table 1. Mean weight loss after dieting was not significant because four patients were still appreciably overweight.

Individual and mean results for OGTT's are given in Table 2 and Figure 1. Mean glucose levels for the first test were slightly above normal because one patient had impaired glucose tolerance which improved after dieting.

IRI responses to the first test showed similar increases to those reported previously in obese children $(7,8)$. In all patients, they lessened after diet (significant difference at $30 \mathrm{~min}$ ). The total insulin response, expressed as the area under the insulin curve, decreased significantly from $174.5 \mu \mathrm{U} / \mathrm{ml} / \mathrm{hr}$ before food restriction to $112.6 \mu \mathrm{U} / \mathrm{ml} / \mathrm{hr}$ afterwards.

IRGIP values were markedly elevated throughout the first test, particularly at fasting, when they rose to three times the control values $(1235 \pm 209 \mathrm{pg} / \mathrm{ml}$ in obese children, and $411 \pm 44 \mathrm{pg} / \mathrm{ml}$ in 8 healthy adults). The rise in the mean GIP concentration to $1515 \pm 158 \mathrm{pg} / \mathrm{ml} 30 \mathrm{~min}$ after glucose ingestion was small and not significantly different from the control values $(1356 \pm 67 \mathrm{pg} /$ $\mathrm{ml}$ ). At $60 \mathrm{~min}$, it had already returned to basal values where it remained thereafter. After diet, basal and postabsorptive IRGIP concentrations diminished markedly in all children, the difference being significant throughout the test, except at $60 \mathrm{~min}$. Total GIP release, as appreciated by the area under the curve, dropped from 3820 before dieting to $1694 \mathrm{pg} / \mathrm{ml} / \mathrm{hr}$ afterwards $(P<0.01)$. In terms of postabsorptive increment, however, there was, on the contrary, a rise from $180 \mathrm{pg} / \mathrm{ml} / \mathrm{hr}$ before dieting to $665 \mathrm{pg} / \mathrm{ml}$ / hr afterwards.

\section{DISCUSSION}

In all five untreated obese children, high basal IRGIP levels were observed, ranging from 900 to $2025 \mathrm{pg} / \mathrm{ml}$ with a mean of $1235 \pm 209 \mathrm{pg} / \mathrm{ml}$. Lack of information about IRGIP concentrations in healthy children certainly limits the physiologic significance of this finding. However, the above IRGIP levels may be considered high when compared to our own control values or to those in the literature $(1,4,5,6,16)$ although both the latter were obtained in adults. To date, the highest basal values observed in man under normal feeding conditions were reported by Creutzfeld et al. (4) who found $742 \pm 188 \mathrm{pg} / \mathrm{ml}$ in obese adults with impaired glucose tolerance. In obese subjects with normal glucose tolerance, basal GIP concentrations also tended to be higher but did not attain statistical significance. In our group, glucose intolerance in one patient (M. S.) was not associated with a particularly elevated basal IRGIP value. The two highest GIP levels at fasting (B. F. and C. S.) were associated with the greatest weight excess.

Following glucose administration, the obese adults studied by Creutzfeld et al. (4) showed significant rises in IRGIP and IRI responses when they were glucose intolerant, but not when their glucose tolerance was normal. In the present study, the mean postabsorptive rise of IRGIP was small and not significantly different from the fasting value. However, the IRI response increased significantly compared to that of healthy children. After three to seven months of moderately restricted food intake which caused no significant weight loss in four out of five children, insulin responses returned to normal ranges, as in previous observations (7). Concomitantly, IRGIP concentrations dropped significantly throughout the test, except at $60 \mathrm{~min}$. Although in the postdiet tests, absolute peak values and total absolute GIP release were both lower than before diet, the postabsorptive increment was markedly higher than that observed before diet, reflecting an improvement in glucose-stimulated GIP release.

Willms et al. (16), who submitted obese adults to caloric restriction, observed unchanged or slightly increased fasting GIP together with decreased basal IRI values. The elevated GIP response to glucose by subjects with glucose intolerance diminished together with their insulin response. These authors suggest that the exaggerated GIP responses by obese subjects are secondary to increased food intake and that changes in the IRI response to PO glucose are related to changes in the IRGIP response. Even though the present finding that dietary measures reverse the postabsorptive insulin hypersecretions associated with reduced basal GIP production differs from the results of Willms et al., it might be compatible with their hypothesis, provided chronic overeating suffices to induce permanent overactivity of the GIP-secreting cells such that elevations of the basal level are constant. This, to say the least, is doubtful, but as long as nothing is known about the mechanism of GIP release induced by nutrients, the question cannot be definitely answered.

The fact that the GIP secretion pattern remains at a constantly high level without significant lowering after a poststimulative rise in circulating insulin might reflect impaired feedback control of GIP secretion by insulin, postulated in obese adults (4), but further studies are necessary to substantiate this hypothesis.

Because of the small number of observations, our data are difficult to correlate. It seems conceivable, however, that the high basal level of GIP observed before diet might, whatever its origin, affect the increased insulin response to glucose. The discrepancy between high GIP and normal insulin levels in the fasting state is not surprising because GIP does not release insulin at fasting blood glucose levels (9). Even though the GIP level after glucose loading is only slightly enhanced, it is sufficiently high to constitute a powerful stimulus for insulin release in the presence of postabsorptive hyperglycemia.

The reason for the insignificant postabsorptive GIP increment prior to caloric restriction is still not clear. One explanation might be that glucose is not a strong enough stimulus to induce GIP hypersecretion, as observed in obese patients with normal glucose tolerance by Creutzfeld et al. (4). Our cases, however, released excessive amounts of insulin, which contradicts the existence of a causal relationship between GIP and insulin secretion.

Another possibility is that in these obese children, the GIP cells

Table 1. The obese children tested: clinical data

\begin{tabular}{|c|c|c|c|c|c|c|}
\hline Patients & Age (yr) & $\begin{array}{l}\text { Age at onset of obesity } \\
\text { (yr) }\end{array}$ & $\begin{array}{l}\text { Duration of obesity } \\
(y r)\end{array}$ & \multicolumn{2}{|c|}{ Degree of obesity (S.D.) } & Duration of diet (mo) \\
\hline B. $\mathbf{Z}$. & $6.7 / 12$ & 3 & 3 & 2.7 & 2.6 & 7 \\
\hline B. F. & $8.7 / 12$ & 3 & 5 & 6.3 & 4.4 & 3 \\
\hline B. $\mathbf{L}$. & $12.8 / 12$ & 9 & 3 & 2.8 & 2.0 & 7 \\
\hline M. S. & $13.3 / 12$ & 8 & 5 & 2.7 & 0.7 & 5 \\
\hline
\end{tabular}




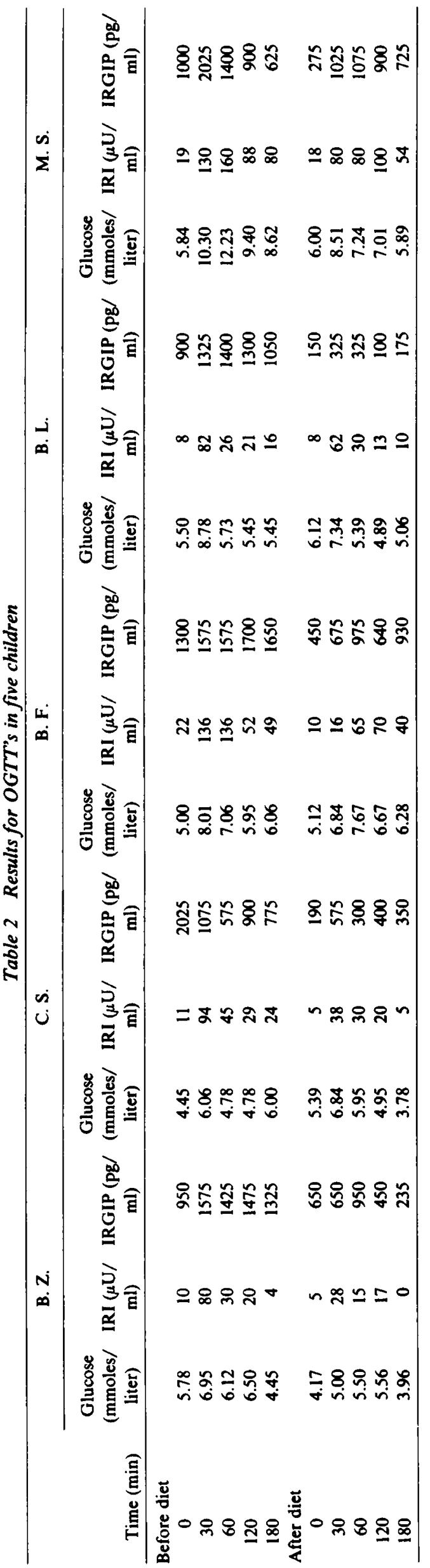

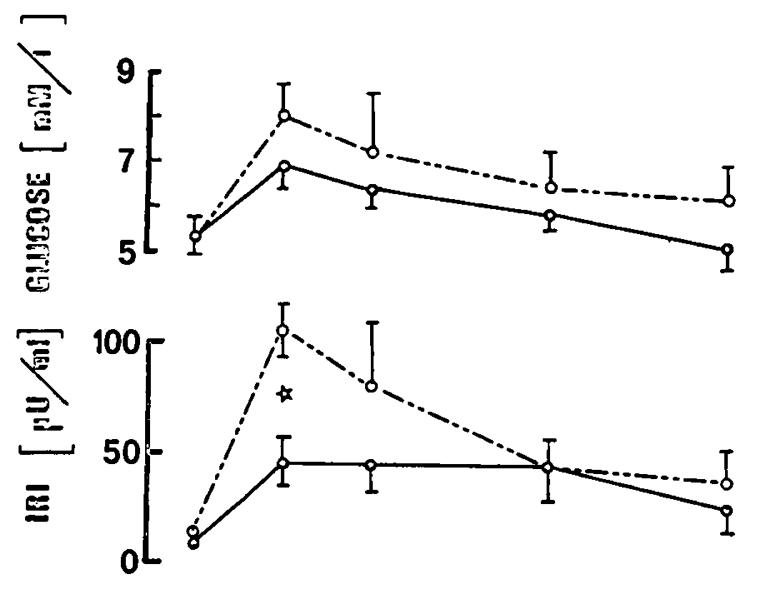

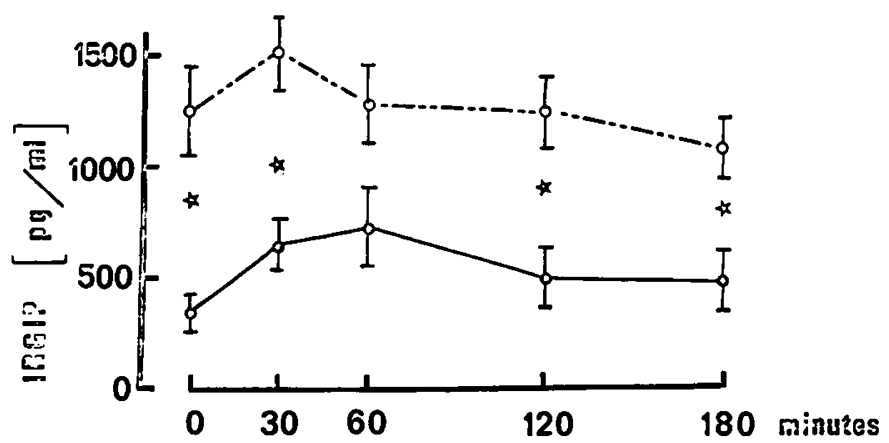

Fig. 1. Plasma glucose, IRI, and IRGIP during OGTT's in five obese children before $(O)$ and after $(O)$ diet. Mean \pm S.E. ${ }^{*}$, significant difference $(P<0.01)$.

reached the limit of their secretory capacity with the high basal secretion and that beyond this limit no additional release could be obtained. However, the question of the origin of this basal GIP hypersecretion still remains unanswered.

Because the present results only include five patients, they cannot claim to elucidate the mechanisms governing GIP release and regulation, but they might help to illustrate the complex nature of the relationships between GIP and insulin secretion and between obesity and food intake.

The changes that restriction of food intake caused in the GIP secretory pattern, which resembled that observed in healthy subjects, suggest that nutritional factors might be responsible for abnormal GIP release in childhood obesity.

\section{REFERENCES AND NOTES}

1. Cataland, S., Crockett, S. E., Brown, J. C., and Mazzaferri, E. L.: Gastric inhibitory polypeptide (GIP) stimulation by oral glucose in man. J. Clin. Endocrinol. Metab., 39: 223 (1974).

2. Creutzfeld, W.: Insulin-releasing factors of the gastrointestinal mucosa (incretin). Gastroenterology, 67: 748 (1974).

3. Creutzfeld, W., Ebert, R., Arnold, R., Frerichs, H., and Brown, J. C.: Gastric inhibitory polypeptide (GIP), gastrin and insulin: response to test meal in coeliac disease and after duodenopancreatectomy. Diabetologia, 12: 279 (1976).

4. Creutzfeld, W. Ebert, R. Willms, B., Frerichs, H., and Brown, J. C.: Gastric inhibitory polypeptide (GIP) and insulin in obesity: increased response to stimulation and defective feedback control of serum levels. Diabetologia, 14: 15 (1978).

5. Crockett, S. E., Cataland, S., Falko, J. M., and Mazzaferri, E. L.: The insulinotropic effect of endogenous GIP in normal subjects. J. Clin. Endocrinol. Metab., 42: 1098 (1976).

6. Crockett, S. E., Mazzaferri, E. L., and Cataland, S.: Gastric inhibitory polypeptide (GIP) in maturity-onset diabetes mellitus. Diabetes, 25: 931 (1976).

7. Deschamps, I., Desjeux, J. F., Machinot, S., Rolland, F., and Lestradet, H.: Effects of diet and weight loss on plasma glucose, insulin and free fatty acids in obese children. Pediatr. Res., 12: 757 (1978).

8. Deschamps, 1., Giron, B. J., and Lestradet, H.: Blood glucose, insulin and free fatty acid levels during OGTTs in 158 obese children. Diabetes, 26: 89 (1977)

9. Dupre, J., Ross, S. A., Matson, D., and Brown, J. C.: Stimulation of insulin secretion by gastric inhibitory polypeptide in man. J. Clin. Endocrinol. Metab., 37: 836 (1973). 
10. Grey, N., and Kipinis, D. M.: Effect of diet composition on the hyperinsulinemia of obesity. N. Engl. J. Med., 285: 827 (1971).

11. Kuzio, M., Dryburgh, J. R., Malloy, K. M., and Brown, J. C.: Radioimmunoassay for gastric inhibitory polypeptide. Gastroenterology, 66: 357 (1974).

12. Olefsky, J., Crapo, P. L. A., Ginsberg, H., and Reaven, R. M.: Metabolic effects of increased caloric intake in man. Metabolism, 24: 495 (1975).

13. Reaven, G. N., and Olefsky, J. M.: Increased plasma glucose and insulin response to high carbohydrate feeding in normal subjects. J. Endocrinol. Metab., 38: 151 (1974).

14. Rodger, N. W., Squires, B. P., and Du, E. L.: Changes in plasma insulin related to the dietary carbohydrates in overweight hyperlipidemia male patients. Can. Med. Assoc. J., 105: 923 (1971)

15. Sims, E. A. H., and Horton, E. S.: Endocrine and metabolic adaptation to obesity and starvation. Am. J. Clin. Nutr., 21: 1455 (1968).

16. Willms, B., Ebert, R., and Creutzfeld, W.: Gastric inhibitory polypeptide (GIP) and insulin in obesity. II. Reversal of increased response to stimulation by starvation or food restriction. Diabetologia, 14: 379 (1978).

17. Yalow, R. S., and Berson, S. A.: Immunoassay of endogenous plasma insulin in man. J. Clin. Invest., 38 : 1157 (1960).

18. Zermatten, A., Ebiner, J. R., De Kalbermatten, N., Curchod, B., Heptner, W., and Felber, J. P.: Elevated duodenal insulin releasing activity (DIRA) in obese and diabetic subjects. IX Internat. Diabetes Federation Congress, New Delhi, Nov. 1976.

19. Zermatten, A., and Felber, J. P.: Influence of intragastric food administration on duodenal insulin-releasing activity (DIRA) in rats. Diabète Métab., 3: 151 (1978).

20. Requests for reprints should be addressed to: I Deschamps, INSERM, U. 83 Hôpital Hérold, 7, place Rhin et Danube, 75935, Paris, France.

21. This research was supported by INSERM grant CRL 7751267 , by Fondation Echanges et Recherches and by L'Aide aux Jeunes Diabètiques.

22. Received for publication December 19, 1978.

23. Accepted for publication June 13, 1979. 